\title{
Article
}

\section{Understanding motives for aggression in forensic psychiatric patients: A preliminary study}

Lewis, Michael and Ireland, Jane Louise

Available at http://clok.uclan.ac.uk/25610/

Lewis, Michael ORCID: 0000-0001-5567-3569 and Ireland, Jane Louise ORCID: 0000-0002-5117-5930 (2019) Understanding motives for aggression in forensic psychiatric patients: A preliminary study. Journal of Forensic Psychiatry and Psychology, 30 (3). pp. 496-509. ISSN 1478-9949

It is advisable to refer to the publisher's version if you intend to cite from the work. http://dx.doi.org/10.1080/14789949.2019.1570541

For more information about UCLan's research in this area go to http://www.uclan.ac.uk/researchgroups/ and search for < name of research Group>.

For information about Research generally at UCLan please go to http://www.uclan.ac.uk/research/

All outputs in CLoK are protected by Intellectual Property Rights law, including Copyright law. Copyright, IPR and Moral Rights for the works on this site are retained by the individual authors and/or other copyright owners. Terms and conditions for use of this material are defined in the policies page.

\section{CLoK}

Central Lancashire online Knowledge www.clok.uclan.ac.uk

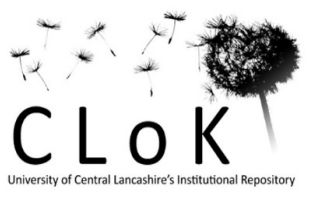


Understanding motives for aggression in forensic psychiatric patients: A preliminary study

Michael Lewis*, Jane L. Ireland

School of Psychology, University of Central Lancashire, Preston, UK

Ashworth Research Centre, Mersey Care NHS Trust, Liverpool, UK

*Correspondence to MLewis9@uclan.ac.uk.

Word count: 5011 
Understanding motives for aggression in forensic psychiatric patients: A preliminary study

\begin{abstract}
The primary aim of this study was to explore motivations underpinning aggression among men detained within conditions of high security. Thirty men residing at a high secure psychiatric hospital completed selfreport measures, including the Aggression Motivation Questionnaire, Revised EXPAGG and Barratt Impulsiveness Scale-IIr. The Historical items of the Historical, Clinical and Risk-Management (HCR-20) and the Psychopathy Checklist-Screening Version were rated. A subsample of participants agreed to complete a functional assessment on an aggressive incident that had occurred during their placement $(n=$ 9). Increased psychopathy and impulsivity, and the presence historical risk items were predicted to associate with higher levels of both aggression motivation and beliefs supportive of aggression. Young age at first violent incident and personality disorder related positively to aggression motivation. Thematic analysis conducted on the functional assessments identified social recognition, emotion regulation, communication and protection as functions underpinning aggression. Results are discussed with regards to their implication for violence treatment and assessment, with a focus on motivation recommended.
\end{abstract}

Keywords: Aggression motivation; Aggression; Functional assessment; SORC; Forensic psychiatry 
Introduction

Capturing aggression motivation is important in understanding why aggression has emerged and how it can be prevented (Ireland, 2018). Motives can be implicit or explicit reasons for engaging in, and performing a given behaviour (Ajzen, 1991). They organise an individual's cognition, emotion and behaviour into coherent action, and therefore become integral when comprehending decisions to aggress. Even a diverse collection of motives have common elements (Reiss, 2004). It is these elements that are salient when attending to treatment needs and aggression management (Ohlsson \& Ireland, 2011).

It is important first to acknowledge that aggression can be separated into two distinct types based on underlying functions, namely proactive and reactive aggression (Dodge \& Coie, 1987). Proactive aggression has been described as instrumental, planned and organised (Ireland, 2018), and generally performed without emotion. It has been linked to social learning models, which purport that maladaptive behaviours, such as aggression, are acquired through observational learning and reinforced over time via perceived or actual reward (Dodge \& Coie, 1987). Reactive aggression, however, is driven by emotion and thought to be uncontrolled and impulsive, often occurring in response to a blocked goal (Ireland, 2018). Motivation is not, however, a binary concept, with individuals presenting with both proactive and reactive motivations. This is referred in the literature as mixed-motive aggressors. Most research, however, has focused on the dichotomy and not the concept of mixed-motives.

Both reactive and proactive has received considerable empirical attention in studies examining aggression motivation among children (e.g. Brown, Fite \& Poquiz, 2016), adolescents (e.g. Euler, Steinlin \& Stadler, 2017) and adults (e.g. Fite, Richey, Dipierro, Brown \& Bortolato, 2016). However, there is comparatively little research exploring the application of such concepts to forensic samples, which is surprising as aggression is readily associated with offenders (Watts \& Howells, 1999) and therefore becomes clinically and theoretically relevant.

Coid (2002) identified numerous motivations to underpin dangerous and disruptive behaviour among a sample of 81 prisoners. Motives included damage to self-esteem, viewing violence as the only 
solution, pride in fighting skills, experiencing minimal stress tolerance, protest, persistent subversion, intolerance of rules, homicidal urges and perceiving provocation. The presence of personality disorder was thought to influence the development of these motives via cognitive bias (e.g. schemas) and consequently, facilitating the enactment of disordered behaviour. Psychopathy was argued to specifically relate to the affective state of hyper-irritability, as well as a predatory tendency to manufacture and conceal weapons.

This conveys a role for both proactive and reactive aggression in psychopathy. Although not well established, the Factor I (i.e. interpersonal/affective) component of psychopathy has been found to be most predictive of proactive aggression as opposed to Factor II (i.e. dissocial behaviour/lifestyle), which is associated more with reactive aggression (Bezdjian, Tuvblad, Raine \& Baker, 2011). More recent research (e.g. Ireland et al., 2018) identified emotion to mediate this relationship, with callous-unemotional traits (Factor I) relating to both proactive and reactive aggression, whereas inhibitory control problems, captured as emotional dysregulation (Factor II), associated more with reactive aggression. Impulsivity, considered a core trait of Factor II psychopathy (Hare, 2003), has also been established as a fundamental characteristic of more expressive or reactive forms of aggressive behaviour (Urben et al., 2018).

Attempts have been made to understand the psychological aspects of aggression exhibited by those residing in mental health settings, with Kockler, Stanford, Nelson, Meloy and Sanford (2006) reporting that $60 \%$ of aggressive patients residing on a secure ward acted impulsively, whilst others behaved in a more calculated manner. Further research sampling of forensic inpatients categorised aggression as manifesting from impaired impulse control, psychopathic traits or psychotic symptoms (Nolan et al., 2003). These findings appear to be missing the functional aspect of aggression, attributing the act solely to psychopathology or structural factors (Daffern, Howells \& Ogloff, 2007; Urheim et al., 2014).

There has been some success when capturing the purpose of aggression occurring within forensic psychiatric settings, with Daffern et al. (2007) noting functions to include expressing anger, tension reduction, forced compliance, demanding avoidance, and promoting social status and approval. At least one function was identified for most incidents, with this resulting in a collective list of motives that can be applied to help discover preventative strategies. 
Indeed, since aggression is described as a heterogeneous concept (Urheim et al., 2014), it is logical to consider that functions may differ within and across populations. Ohlsson and Ireland (2011) noted this among a sample of prisoners $(n=206)$, reporting four salient motives; Protection; Social recognition; Positive outcome; and Pleasure. Violent and nonviolent offenders differed on their underlying motives for recent acts of aggression, which was consistent with the work of Gudjonsson and Sigurdsson (2007), who proposed that delinquent behaviour could be accounted for by a specific pattern of personality traits, with these traits relating to certain motives. Violent offenders were more likely to cite motives of positive outcome and pleasure for their aggression when compared to those with non-violent convictions.

Ohlsson and Ireland (2011) found no preference for reactive or proactive motivation, noting how aggression motives are understood best as mixed-motived, with these motivates more complex than initially proposed. A theoretical model has been offered to capture aggression motives in forensic populations, namely the Applied Integrated Model of Aggression (AIM-AM; Ohlsson, 2018). This proposes that the underlying core characteristics of aggression and non-aggression comprise of multiple components, including developmental, affect, cognitive and personality factors.

According to AIM-AM, developmental factors and adverse life experiences, such as insecure attachments (Bowlby, 1988), promote aggression as these influence cognition, as well as emotion regulation and personality functioning (Hoeve et al., 2012), and consequently, the appraisal and decision-making processes relevant to aggressive responding. It is essentially the nature, content and combination of these factors thought to dictate the outcome (i.e. aggression or non-aggression; Ohlsson, 2018). As yet, there has been no application of this model to studies outside of the original development datasets. In addition, there has been no attempt to integrate models of aggression motivation with well-developed means of assessing risk for violence in forensic populations, such as the Historical, Clinical and Risk-Management-20v2 (HCR20v2; Webster, Douglas, Eaves \& Hart, 1997). This is surprising since clinical formulation would arguably benefit from an integrated approach where aggression is understood via function, risk factors, and the interaction between them. 
Thus, what becomes apparent is that aggression motivation and its relationship with factors, such as psychopathy, impulsivity and developmental risk factors remains poorly understood among forensic populations. This extends to secure psychiatric settings where aggression has been described by some as motiveless (Daffern \& Howells, 2002). A lack of motivation has been viewed as characteristic of offenders with mental health challenges, and as such, assessing for the function of aggression among this population appears contradictory (Daffern \& Howells, 2002). Historical views like these are unhelpful and inconsistent with modern interventions designed to reduce risk of aggression, where there is increased recognition of an absence of motiveless aggression (Ireland, 2018).

The present research aims to begin to address the gap in the literature in forensic (psychiatric) populations by establishing the function of aggression and clarifying the presence of the reactive and proactive dichotomy within such a sample. It is predicted that: 1). The historical risk factors of the HCR$20 v 2$ will all positively relate to aggression motivation; 2). Psychopathy will positively relate to aggression motivation; 3). Increased levels of psychopathy will associate with higher levels of beliefs supportive of aggression; and 4). Higher levels of impulsivity will correlate with increased levels of beliefs supportive of aggression.

\section{Method}

\section{Participants}

Thirty men aged 18 years and over, detained in a high secure psychiatric hospital, took part. All had a documented history of aggression. Using data obtained from the HCR-20v2, major mental illness was definitely present in 27 participants, with 14 of these also having a formal diagnosis of personality disorder. Twenty-three participants were rated as exhibiting difficulties with substances. A subsample $(n=9)$ agreed to complete a functional assessment of an aggressive incident. The remainder of the sample refused to engage with this aspect of the research.

\section{Materials}


Revised EXPAGG (Archer \& Haigh, 1997): A 16-item self-report measure assessing instrumental and expressive beliefs towards aggression. Instrumental beliefs were captured through eight items such as, 'I feel that physical aggression is necessary to get through to some people'. Expressive beliefs were captured by eight items (e.g. 'I believe that my aggression comes from losing my self-control'). All items were rated on a five-point Likert scale: (1) 'strongly disagree' to (5) 'strongly agree'.

Barratt Impulsiveness Scale-IIr (BIS-IIr; Barratt, 1994): This modified version of the BIS-II assessed impulsively across contexts. Items such as, 'I have racing thoughts', were rated via a four-point Likert scale: (1) 'rarely/never' to (4) 'almost always/always'. Two items were removed as they were not suitable for forensic (or detained) samples: 'I plan for job security' and 'I change where I live'.

Aggression Motivation Questionnaire (AMQ; Ireland, 2008): A 46-item questionnaire scored on a five-point Likert scale: (1) 'totally disagree' to (5) 'totally agree'. The measure assessed motivations for aggression through (Ohlsson \& Ireland, 2011): Protection (e.g. 'I have had to defend myself'); Social recognition (e.g. 'I wanted to gain a reputation'); Positive outcome (e.g. 'I believed it would have a positive outcome for me'); and Pleasure (e.g. 'I have been fantasising about using aggression').

Participants also completed the SORC functional assessment (Lee-Evans, 1994) via interview. The SORC (S-timuli [triggers], O-rganism [historical factors], R-esponses [resulting behaviour] and C-onsequences [reinforcers]) is completed collaboratively, allowing for the function of behaviour to be explored. In this instance focus was on an aggressive incident that had occurred during the patient's placement.

The following were completed using collateral information taken from hospital records:

Historical, Clinical and Risk-Management-20v2 - Historical items (HCR-20v2; Webster et al., 1997): The ten rated items were previous violence, young age at first violent incident, relationship instability, employment problems, substance use problems, major mental illness, psychopathy, early maladjustment, personality disorder and prior supervision failure. Each item was rated from (0) 'not present' to (2) 'definitely present'. 
Psychopathy Checklist: Screening Version (PCL:SV; Hart, Cox \& Hare, 1995): This screens for psychopathy. Items were rated from (0) 'item does not apply' to (2) 'item definitely applies'. The PCL:SV consists of two factors; factor one (six items, e.g. 'superficial' and 'deceitful'): interpersonal style, and factor two (e.g. 'impulsive' and 'lacks goals'): criminal history and lifestyle.

\section{Procedure}

Ethical approval was obtained and Responsible Clinicians provided consent for patients to be involved prior to them being approached. All patients received information surrounding the study before completing the measures. It was emphasised that the research would remain anonymous and individual responses would be reported only as part of group data. Patients were debriefed following involvement. Qualitative data was analysed using thematic analysis and quantitative, using SPSS. Thematic analysis was applied to the SORC functional assessments to identify themes among aggressive incidents noted. There were six stages involved (Braun \& Clarke, 2006): 1). Data familiarisation; 2). Initial coding; 3). Searching for themes; 4). Reviewing the themes; 5). Defining and labelling the themes; and 6). Writing the report.

\section{Results}

\section{Quantitative analysis: Data screening}

Data screening indicated no multivariate outliers or extreme univariate outliers. No missing data was replaced.

\section{Aggression motivation, trait aggression and impulsivity}

Descriptive statistics and reliabilities analyses were calculated for all psychometrics (see Table 1). Higher mean scores were indicative of increased levels of the respective construct.

\section{Table one goes about here}


Internal consistency was acceptable across measures accounting for the number of items. This did not extend to the expressive EXPAGG subscale $(\alpha=.29)$, which was consequently excluded from ensuing analyses.

Tests of difference highlighted significant disparity $(t \geq 2.54, p<.05)$ between the various forms of aggression motivation, as measured via the AMQ (i.e. protection, social recognition, pleasure and positive outcome). Protection was the most common motive. There was no difference, however, between levels of social recognition and positive outcome $(t=1.23, p>.05)$.

Psychopathy and the HCR-20v2 historical items

Internal consistency was acceptable across both clinical measures. Descriptive statistics are presented in Table 2.

\section{Table two goes about here}

There was no significant difference in psychopathy ratings between the two PCL:SV factors $(t$ (6) $=-2.07, p>.05)$.

\section{Relationships with aggression motivation}

Bivariate correlations were performed to identify associations between aggression motivation, beliefs relevant to instrumental aggression, psychopathy, impulsivity and the historical items of the HCR$20 v 2$.

Young age at first violent incident (HCR-20), was associated with increased levels of aggression motivation as a global score $(r=.54, p<.01, n=24)$, as well as protection $(r=.48, p<.01, n=24)$, social recognition $(r=.45, p<.01, n=24)$, positive outcome $(r=.56, p<.01, n=24)$ and pleasure $(r=.45, p<$ $.01, n=24)$. The presence of personality disorder (HCR-20v2) correlated with increased levels of protection 
$(r=.42, p<.01, n=27)$. All significant correlations were moderate in strength. There were no further significant findings.

\section{Qualitative analysis: Determining function(s) of aggression using the SORC}

Thematic analysis was conducted on the completed SORC assessments $(n=9)$. Four participants described an incident of physical aggression, one of which included the use of a weapon. A further four discussed an incident relating to verbal aggression, and one noted the use of mixed aggression (i.e. verbal and physical aggression). Twenty themes were demonstrated, presented in Table 3. Inter-rater reliability of the themes was considered with another rater, producing overall agreement of $73.7 \%$ (Cohen's Kappa $=$ $.73, \mathrm{p}<.001)$

\section{Table three goes about here}

Discussion

The findings clarified the presence of the reactive and proactive dichotomy, identifying protection as the most prevalent motive, as assessed via the AMQ. This emphasised the importance of attending to prior experiences when understanding aggression among forensic populations, such as developmental experiences. For example, negative childhood experiences, specifically maltreatment, feature strongly in the developmental profile for protection motivated aggressors (Ohlsson, 2018). Similar early experiences are also shared across profiles for aggressors directed by pleasure or positive outcome, but to a lesser extent.

Four broad functions were derived from the SORC functional assessments, protection, social recognition, emotion regulation and communication. This further supported protection as a core motive for aggression, as well as a need to extend aggression classification systems. The motives exhibited by the sample shared consistency with previous research (Daffern et al., 2007; Ohlsson \& Ireland, 2011). 
Communication as an aggression function appeared specific to the present sample and has not been identified among prisoner samples (e.g. Ohlsson \& Ireland, 2011). Aroused or irritable patients are likely to be sensitive to provocation and it may be that aggression serves as a means of communicating their dissatisfaction when requests are denied or perceived as annoying, unfair, disrespectful or unjust (Daffern et al., 2007). Patients in the present study who were particularly mentally unwell may also use aggression when responding to auditory hallucinations and this could be directed at others as a way of expressing their frustration. Further research on communication and aggression among forensic (psychiatric) samples is warranted, as the link between the two cannot be determined by the current data.

Multiple factors pertinent to the development, expression and maintenance of aggression were found. Twenty themes were identified from the SORCs, detailing individual and collective deficits that inhibit prosocial behaviour and promote aggression. This included a number of core beliefs (e.g. "Fighting is a good way of communicating anger" and "Aggression is justified if somebody deserves it") that would be omitted if aggression motivation was understood through self-report alone. The SORC also identified themes (e.g. environment and culture, negative affect, attitudes towards aggression, etc.) consistent with the AIM-AM, thus extending its application to forensic psychiatric populations, as well as indicating that developmental factors are not solely responsible for aggression with other aspects, such as cognition, affect and personality, important (Ohlsson, 2018). This shifts the focus from a simplistic sequential or parallel application, to a comprehensive framework when accounting for the etiological pathways of aggression in this specialised population.

The presence of personality disorder as a factor related to increased levels of aggression motivation on the AMQ subscale protection, further reinforces the link between developmental experiences and cognition captured by the AIM-AM, as personality disorder is known to influence the manifestation of aggression motivation through underlying cognitive schemas (Coid, 2002). It could be speculated that those patients diagnosed with personality challenges had been exposed to adverse early experiences, such as childhood trauma or abuse, giving rise to enduring beliefs supportive of a hostile world where protection is required. Young age at first violent incident positively associated with all AMQ motivations, including 
protection, which can also be associated with personality challenges, where early behaviour difficulties are acknowledged. It suggest value in exploring the developmental link between personality and aggression motivation in this sample, in more detail. Interestingly, both psychopathy and impulsivity did not exhibit a relationship with aggression motivation or beliefs supportive of aggression. This was unexpected, particularly considering an association with personality disorder. It was inconsistent with the predictions, based on findings that both psychopathy and impulsivity are readily linked with aggression motivation (e.g. Bezdjian et al., 2011; Urben et al., 2018), highlighting again the value in exploring the link between personality and its markers (such as trait impulsivity), in more detail.

What is clear, is that aggression among forensic psychiatric patients is driven by a variety of functions, with the behaviour itself potentially proving to be a successful strategy at achieving these from an early age. It is not clear which of the aggression motives underpin the continuity of aggression due to the cross-sectional design of the study. However, the results do emphasise the heterogeneity of aggression motivation within the sample, emphasising the value in considering aggression on an individual basis (e.g. Ireland, 2018).

There was no association between the remaining historical items of the HCR-20v2 and aggression motivation. This was surprising considering as emphasis placed on historical items as associated with aggression (Webster et al., 1997). Only partial support was therefore found for the hypothesis predicting a relationship between the HCR-20v2 historical items and aggression motivation, suggesting again that aggression motivation, as opposed to aggression type, has been neglected in the development of aggression risk prediction.

This preliminary study is not without limitations. The number of participants sampled were small and thus generalising findings to other forensic populations should be conducted with caution. Future research should consider testing a greater number of patients across forensic psychiatric services nationally, as well as extending the recruitment criteria to women, thus investigating sex differences within aggression motivation. Self-report has also come under scrutiny when used to examine sensitive behaviours, such as aggression. Whilst impression management may have occurred, Ray et al. (2013) acknowledge that 
offenders are often willing to admit their undesirable traits and behaviours. Functional assessment, however, presented as a promising approach when exploring an aggressive event collaboratively with patients. It provided a holistic understanding beyond that offered via self-report; identifying function, as well as core beliefs conducive to aggression.

Even accounting for its limitations, this study offers valuable insight into the motives for aggression among a forensic psychiatric sample. It emphasised the benefits of considering aggression motivation in extreme populations as a comprehensive framework rather than simple dichotomy; one that can be better informed via approaches that take into account factors occurring before, during and after the event. Aggression appeared to serve several functions among the sample, with protection being of particular importance and highlighting a need for treatment to consider alternative strategies for coping with challenging situations where hostile intent is interpreted.

Further research should continue to explore the structure of specific motivations for aggression across a period of time to assess whether developmental factors, such as adverse childhood experiences, directly or indirectly, influence aggressive responding. This will also help further refine theories, such as the AIM-AM, to better capture the etiological pathways to aggression among forensic psychiatric patients, informing individual treatment needs and risk management.

\section{References}

Ajzen, I. (1991). The theory of planned behaviour. Organizational Behavior and Human Decision Processes, 50(2), 179-211.

Archer, J., \& Haigh, A. (1997). Do beliefs about aggressive feelings and actions predict reported levels of aggression? British Journal of Social Psychology, 36(1), 83-105.

Barratt, E. S. (1994). Impulsiveness and aggression. In J. Mohanan, \& J. Steadman (Eds.), Violence and mental disorder (pp. 61-79). Chicago: University of Chicago Press. 
Bezdjian, S., Tuvblad, C., Raine, A., \& Baker, L. A. (2011). The genetic and environmental covariation among psychopathic personality traits, and reactive and proactive aggression in childhood. Child Development, 82(4), 1267-1281.

Bowlby, J. (1988). A secure base: Parent-child attachment and healthy human development. New York: Basic Books.

Braun, V., \& Clarke, V. (2006). Using thematic analysis in psychology. Qualitative Research in Psychology, 3(2), 77-101.

Brown, S., Fite, P. J., \& Poquiz, J. (2016). Moderating effects of gender on outcomes associated with stressful life events among elementary school-age youth. Child Psychiatry and Human Development, 47(4), 593-602.

Coid, J. W. (2002). Personality disorders in prisoners and their motivation for dangerous and disruptive behaviour. Criminal Behaviour and Mental Health, 12(3), 209-226.

Daffern, M., \& Howells, K. (2002). Psychiatric inpatient aggression: A review of structural and functional assessment approaches. Aggression and Violent Behavior, 7(5), 477-497.

Daffern, M., Howells, K., \& Ogloff, J. (2007). What's the point? Towards a methodology for assessing the function of psychiatric inpatient aggression. Behaviour Research and Therapy, 45(1), 101-111.

Dodge, K. A., \& Coie, J. (1987). Social information-processing factors in reactive and proactive aggression in children's peer groups. Journal of Personality and Social Psychology, 53(6), 1146-1158.

Euler, F., Steinlin, C., \& Stadler, C. (2017). Distinct profiles of reactive and proactive aggression in adolescents: Associations with cognitive and affective empathy. Child and Adolescent Psychiatry and Mental Health, 11(1), 1-14.

Fite, P. J., Richey, A., Dipierro, M., Brown, S., \& Bortolato, M. (2016). Associations between proactive and reactive aggression and risky sexual behaviour among emerging adults. Journal of Aggression, Maltreatment and Trauma, 25(10), 1131-1148.

Gudjonssen, G. H., \& Sigurdsson, J. F. (2007). Motivations for offending and personality: A study among young offenders on probation. Personality and Individual Differences, 42(7), 1243-1253. 
Hare, R. D. (2003). Manual for the revised Psychopathy Checklist Revised 2. Toronto: Multi-Health Systems.

Hart, S. D, Cox, D., \& Hare, R. D. (1995). Manual for the Psychopathy Checklist: Screening Version (PCL:SV). Toronto: Multi-Health Systems.

Hoeve, M., Stams, G. J. J. M., van der Put, C. M., Semon Dubas, J., van der Laan, P. H., \& Gerris, J. R. M. (2012). A meta-analysis of attachments to parents and delinquency. Journal of Abnormal Child Psychology, 40(5), 771-785.

Ireland, J. L. (2008). Conducting individualised theory-driven assessments of violent offenders. In J. L. Ireland, C. A. Ireland, \& P. Birch (Eds.), Violent and sexual offenders: Assessment, treatment and management (pp. 68-96). Devon: Willan Publishing.

Ireland, J. L. (2018). Individual assessments of aggression: Accounting for core factors. In J. L. Ireland, C. A. Ireland, \& P. Birch (Eds.), Violent and sexual offenders: Assessment, treatment and management (2nd ed., pp. 203-227). Abingdon: Routledge.

Ireland, J. L., Lewis, M., Ireland, C. A., Derefaka, G., Taylor, L., McBoyle, J., Smillie, L. Chu, S., \& Archer, J. (2018). Self-reported psychopathy and aggression motivation: A role for emotions? Manuscript in preparation.

Kockler, T. R., Standford, M. S., Nelson, C. E., Meloy, J. R., \& Sanford, K. (2006). Characaterizing aggressive behavior in a forensic population. American Journal of Orthopsychiatry, 76(1), 80-85.

Lee-Evans, J. M. (1994). Background to behavioural analysis. In M. McMurran, \& J. Hodge (Eds.), The assessment of criminal behaviours of clients in secure settings (pp. 6-33). London: Jessica Kingsley Publishers.

Nolan, K. A., Czobor, P., Roy, B. B., Platt, M. M., Shope, C. B., Citrome, L.L., \& Volavka, J. (2003). Characteristics of assaultive behavior among psychiatric inpatients. Psychiatric Services, 54(7), $1012-1016$. 
Ohlsson, I. M. (2018). Aggression motivation and inhibition: Theoretical underpinnings and a new model. In J. L. Ireland, P. Birch, \& C. A. Ireland (Eds.), The Routledge International Handbook of Human Aggression (pp. 64-69). Abingdon: Routledge.

Ohlsson, I. M., \& Ireland, J. L. (2011). Aggression and offence motivation in prisoners: Exploring the components of motivation in an adult male sample. Aggressive Behavior, 37(3), 278-288.

Ray, J. V., Hall, J., Rivera-Hudson, N., Poythress, N. G., Lilienfeld, S. O., \& Morano, M. (2013). The relation between self-reported psychopathic traits and distorted response styles: A meta-analytic review. Personality Disorders: Theory, Research and Treatment, 4(1), 1-14.

Reiss, S. (2004). Multifaceted nature of intrinsic motivation: The theory of 16 basic desires. Review of General Psychology, 8(3), 179-193.

Urben, S., Habersaat, S., Pihet, S., Suter, M., de Ridder, J., \& Stéphan, P. (2018). Specific contributions of age of onset, callous-unemotional traits and impulsivity to reactive and proactive aggression in youths with conduct disorders. Psychiatric Quarterly, 89(1), 1-10.

Urheim, R., Rypdal, K., Melkevik, O., Hoff, H. A., Mykletun, A., \& Palmstierna, T. (2014). Motivational dimensions of inpatient aggression. Criminal Behaviour and Mental Health, 24(2), 141-150.

Watts, B. D., \& Howells, K. (1999). Skills training for aggression control: Evaluation of an anger management programme for violent offenders. Legal and Criminological Psychology, 4(2), 285300 .

Webster, C. D., Douglas, K. S., Eaves, D., \& Hart, S. D. (1997). HCR-20 assessing riskfor violence (version two). Vancouver: Mental Health, Law and Policy Institute, Simon Fraser University. 
Table 1. Descriptive statistics for aggression motivation, instrumental and expressive beliefs, and impulsivity (SD in parentheses).

\begin{tabular}{|c|c|c|c|c|c|c|}
\hline & $n$ & Mean (SD) & $\begin{array}{r}\text { Min/Max } \\
\text { attainable } \\
\text { score }\end{array}$ & $\alpha$ & Skewness & Kurtosis \\
\hline \multicolumn{7}{|l|}{ EXPAGG Aggression: } \\
\hline Expressive & 25 & $22.20(6.56)$ & $8.0 / 40.0$ & .29 & -.09 & .12 \\
\hline Instrumental & 24 & $19.88(7.63)$ & $8.0 / 40.0$ & .66 & -.12 & -1.43 \\
\hline $\begin{array}{l}\text { Barratt Impulsiveness Scale } \\
\text { (BIS-IIr): }\end{array}$ & 26 & $56.19(13.45)$ & $28.0 / 112.0$ & .83 & .54 & .09 \\
\hline Aggression Motivation & 27 & 115.15 & $46.0 / 230.0$ & .96 & -.06 & -1.14 \\
\hline Questionnaire (AMQ): & & $(42.98)$ & & & & \\
\hline Protection & 27 & $41.26(14.65)$ & $13.0 / 65.0$ & .90 & -.37 & -.95 \\
\hline Social recognition & 27 & $27.15(13.71)$ & $12.0 / 60.0$ & .92 & .50 & -1.28 \\
\hline Positive outcome & 27 & $25.04(10.03)$ & $10.0 / 50.0$ & .80 & .21 & -.62 \\
\hline Pleasure & 27 & $21.70(9.98)$ & $11.0 / 55.0$ & .84 & .70 & -.41 \\
\hline
\end{tabular}


Table 2. Descriptive statistics for psychopathy and the HCR-20v2 historical items (SD in parentheses).

\begin{tabular}{|c|c|c|c|c|c|c|}
\hline & $n$ & Mean (SD) & $\begin{array}{r}\text { Min/Max } \\
\text { attainable score }\end{array}$ & $\alpha$ & Skewness & Kurtosis \\
\hline Psychopathy Checklist: & 27 & $9.70(4.61)$ & $0.0 / 24.0$ & .81 & .18 & -1.11 \\
\hline \multicolumn{7}{|l|}{ Screening Version } \\
\hline \multicolumn{7}{|l|}{ (PCL:SV): } \\
\hline Factor I & 11 & $4.45(2.94)$ & $0.0 / 12.0$ & .74 & 1.03 & 1.06 \\
\hline Factor II & 18 & $7.11(3.00)$ & $0.0 / 12.0$ & .73 & -.72 & -.91 \\
\hline Historical, Clinical, Risk- & 23 & $14.57(3.53)$ & $0.0 / 20.0$ & .75 & -1.01 & .74 \\
\hline \multicolumn{7}{|l|}{ Management - 20v2 (HCR- } \\
\hline \multicolumn{7}{|l|}{ 20v2): } \\
\hline Previous violence & 27 & $1.96(.19)$ & $0.0 / 2.0$ & - & -5.20 & 27.00 \\
\hline Young age at first & 27 & $1.59(.57)$ & $0.0 / 2.0$ & - & -1.06 & .24 \\
\hline \multicolumn{7}{|l|}{ violent incident } \\
\hline Relationship instability & 24 & $1.63(.65)$ & $0.0 / 2.0$ & - & -1.56 & 1.42 \\
\hline Employment problems & 27 & $1.15(.86)$ & $0.0 / 2.0$ & - & -.30 & -1.62 \\
\hline Substance use problems & 27 & $1.37(.74)$ & $0.0 / 2.0$ & - & -.74 & -.74 \\
\hline Major mental illness & 27 & $2.00(.00)$ & $0.0 / 2.0$ & - & - & - \\
\hline Psychopathy & 28 & $.40(.57)$ & $0.0 / 2.0$ & - & 1.11 & .36 \\
\hline Early maladjustment & 27 & $1.48(.80)$ & $0.0 / 2.0$ & - & -1.14 & -.39 \\
\hline Personality disorder & 30 & $.77(.86)$ & $0.0 / 2.0$ & - & .49 & -1.48 \\
\hline Prior supervision failure & 26 & $1.54(.76)$ & $0.0 / 2.0$ & - & -1.32 & .19 \\
\hline
\end{tabular}

Note. Alphas were not determined for the historic factors of the HCR-20v2 as each was underpinned by a single item. 
Table 3. Themes identified from SORC assessments.

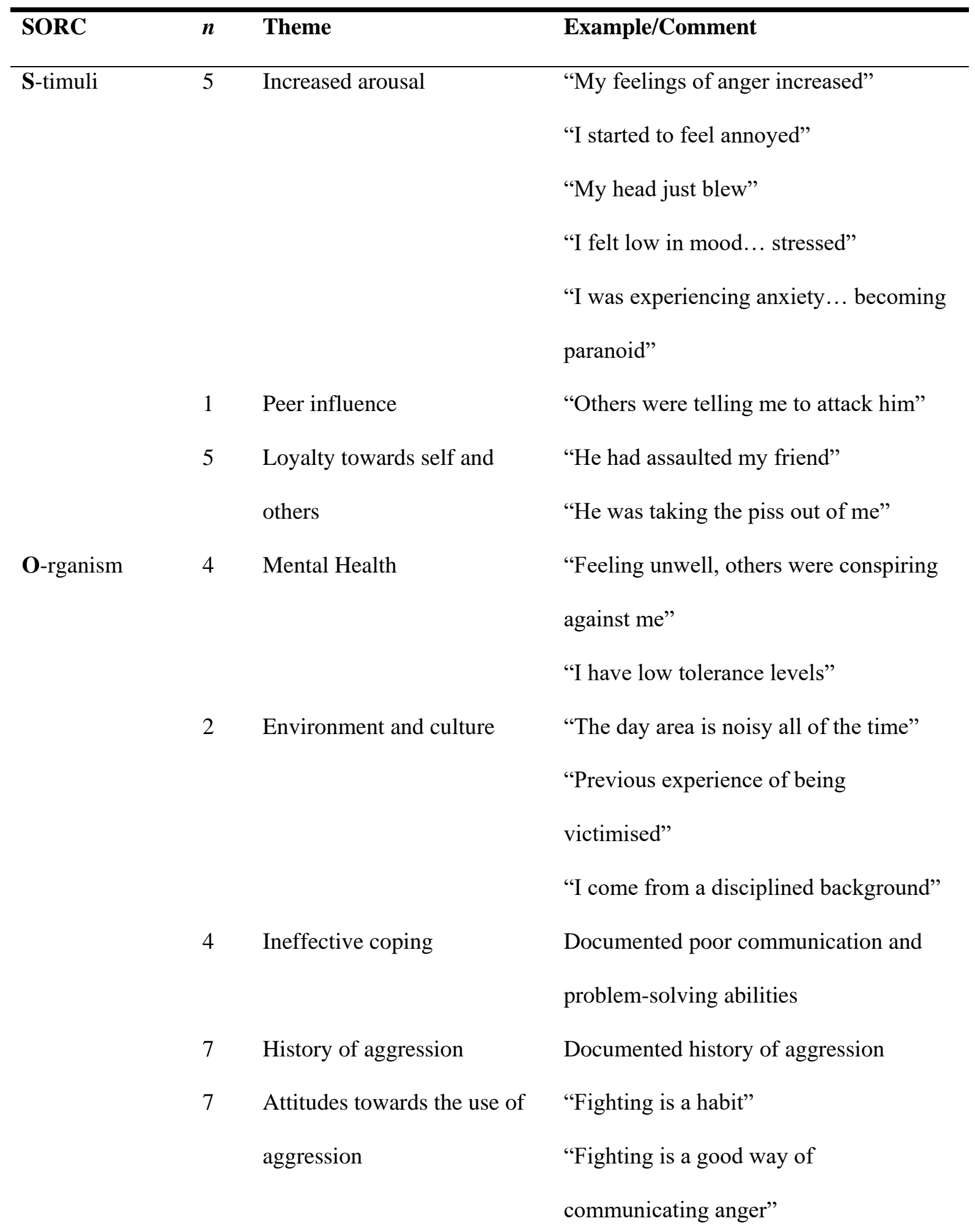


"Aggression is justified if somebody

deserves it"

R-esponse

4

5

Verbal aggression

Physical aggression

1 Mixed aggression

C-onsequences 2 Positive outcome

$5 \quad$ Reinforcing status and boundaries

$4 \quad$ Negative affect

3

Harming others and self
"I shouted at the other guy to shut up"

"Use of a weapon"

"The other guy retaliated which led to a

fight"

"It went from verbal to physical"

"Friend felt happy that I had stuck up for

him"

"I settled well on the new ward"

"I no longer have to talk to the guy"

"I had gained support from others"

"I felt better, nobody takes the piss out of

me... he is now scared of me"

"Boundaries between him and me had

been re-established"

"Staff intervened and I was secluded"

"I felt disappointed with my actions"

"Increased feelings of anger"

"I felt a bit numb"

"I felt regret"

"I broke his nose"

"I wanted to hurt the others who had put

him there"

"I later refused to eat any food" 
"I stayed in my room and ruminated for a couple of days"

F-unction

4 Social recognition

5 Emotion regulation

5 Communication

2 Protection
"To save face in front of others"

"I wanted to establish a hierarchy"

"I needed to teach him a lesson, he was pushing boundaries"

"To release feelings of anger"

"To release frustration"

"I wanted to stop others being noisy"

"I wanted to communicate feeling of

dissatisfaction"

"I reacted to perceived provocation" 